Article

\title{
Alkylphenol Activity against Candida spp. and Microsporum canis: A Focus on the Antifungal Activity of Thymol, Eugenol and $\boldsymbol{O}$-Methyl Derivatives
}

\author{
Raquel O.S. Fontenelle ${ }^{1, *}$, Selene M. Morais ${ }^{2}$, Erika H.S. Brito ${ }^{3}$, Raimunda S.N. Brilhante ${ }^{4}$, \\ Rossana A. Cordeiro ${ }^{4}$, Ynayara C. Lima ${ }^{5}$, Nilce V.G.P.S. Brasil ${ }^{5}$, André J. Monteiro ${ }^{6}$ \\ José J.C. Sidrim ${ }^{4}$ and Marcos F.G. Rocha ${ }^{4,7}$
}

1 Centre of the Agricultural Sciences and Biological, Acaraú Valley State University, 62040-370, Sobral, CE, Brazil

2 Department of Chemistry, State University of Ceará, 60740-000, Fortaleza, CE, Brazil; E-Mail: selene@uece.br

3 Department of the Veterinary, Faculty of Veterinary Medicine, Superior Institute of Applied Theology, 62050-100, Sobral, CE, Brazil; E-Mail: sallesbrito@yahoo.com.br

4 Department of Pathology and Legal Medicine, Faculty of Medicine, Medical Mycology Specialized Center, Federal University of Ceará, 60441-750, Fortaleza, CE, Brazil; E-Mails: brilhante@ufc.br (R.S.N.B.); ross_aguiar@yahoo.com.br(R.A.C.); sidrim@ufc.br(J.J.C.S.); mfgrocha@gmail.com (M.F.G.R.)

5 Department of Organic and Inorganic Chemistry, Federal University of Ceará, 60455-760, Fortaleza, CE, Brazil; E-Mails: yna.colares@gmail.com (Y.C.L.)

Nilcegramosapompeu@yahoo.com.br (N.V.G.)

6 Department of Statistics and Applied Mathematics, Federal University of Ceará, 60455-760, Fortaleza, CE, Brazil; E-Mail: jalles@ufc.br

7 Postgraduate Program in Veterinary Science, State University of Ceará, 60740-000, Fortaleza, CE, Brazil

* Author to whom correspondence should be addressed; E-Mail: raquelbios@yahoo.com.br; Tel.: +55-81-8104-0745. Fax: +55-85-3495-8692.

Received: 11 May 2011; in revised form: 15 July 2011 / Accepted: 26 July 2011 /

Published: 29 July 2011

Abstract: In recent years there has been an increasing search for new antifungal compounds due to the side effects of conventional antifungal drugs and fungal resistance. 
The aims of this study were to test in vitro the activity of thymol, eugenol, estragole and anethole and some $O$-methyl-derivatives (methylthymol and methyleugenol) against Candida spp. and Microsporum canis. The broth microdilution method was used to determine the minimum inhibitory concentration (MIC). The minimum fungicidal concentrations (MFC) for both Candida spp. and M. canis were found by subculturing each fungal suspension on potato dextrose agar. Thymol, methylthymol, eugenol, methyleugenol, anethole, estragole and griseofulvin respectively, presented the following MIC values against $M$. canis: 4.8-9.7; 78-150; 39; 78-150; 78-150; 19-39 $\mu \mathrm{g} / \mathrm{mL}$ and 0.006-2.5 $\mu \mathrm{g} / \mathrm{mL}$. The MFC values for all compounds ranged from 9.7 to $31 \mu \mathrm{g} / \mathrm{mL}$. Concerning Candida spp, thymol, methylthymol, eugenol, methyleugenol, anethole, estragole and amphotericin, respectively, showed the following MIC values: 39; 620-1250; $150-620 ; 310-620 ; 620 ; 620-1250$ and $0.25-2.0 \mu \mathrm{g} / \mathrm{mL}$. The MFC values varied from 78 to $2500 \mu \mathrm{g} / \mathrm{mL}$. All tested compounds thus showed in vitro antifungal activity against Candida spp. and M. canis. Therefore, further studies should be carried out to confirm the usefulness of these alkylphenols in vivo.

Keywords: thymol; eugenol; estragole; methyl-derivatives; dermathophytes; Candida

\section{Introduction}

Dermatophytosis is the most important superficial mycoses in both humans and animals. This clinical condition is caused by a group of related filamentous fungi of the genera Epidermophyton, Microsporum and Trichophyton [1]. The conventional treatment of fungal diseases is limited compared to antibiotic therapy for bacterial infections [2]. Treatment of dermatophyte infection involves primarily oral and/or topical formulations of azoles or allylamines, particularly itraconazole and terbinafine [3]. More recently, the increasing problems of antifungal drug resistance of dermatophytic fungi have been described [4].

The various forms of candidiasis are the most frequent causes of fungal infection in humans. A progressive increase in the frequency of candidemia has been observed, particularly among patients receiving antibiotics, immunosuppressive therapy or parenteral nutrition, as well as among patients exposed to invasive medical procedures [5]. Antifungal resistance in Candida spp strains has been observed in both humans and animals [5-7]. The resistance of Candida spp to currently available antifungal drugs represents a major challenge for future empirical therapeutic and prophylactic strategies.

Therefore, numerous essential oils have been tested for both their in vitro and in vivo antimycotic activity. These oils have great potential as antifungal agents for use alone or together with standard antifungal therapies [2]. Essential oils that contain alkylphenols such as thymol, eugenol, estragole, and anethole have demonstrated antifungal properties [8-12].

Our previous studies with essential oils from species of Crotons [10] and Lippia sidoides [8] have shown their antifungal activity against Candida spp. and M. canis. In the GC/MS analysis of these oils, the main constituent found in the essential oil of L. sidoides was thymol, while in the essential oil of 
Croton nepetaefolius this was methyleugenol and for Croton zenhtneri its was estragole/anethole. Based on these studies, the present research was carried out to evaluate the antifungal activity of alkylphenols (thymol, eugenol, estragole and anethole) and $O$-methyl-derivatives of thymol and eugenol (Figure 1) against Candida spp. and M. canis in vitro. The $O$-methyl-derivatives were obtained by reaction of the phenolic group with dimethyl sulfate in alkaline medium [13].

Figure 1. Chemical structures of antifungal alkylphenols.

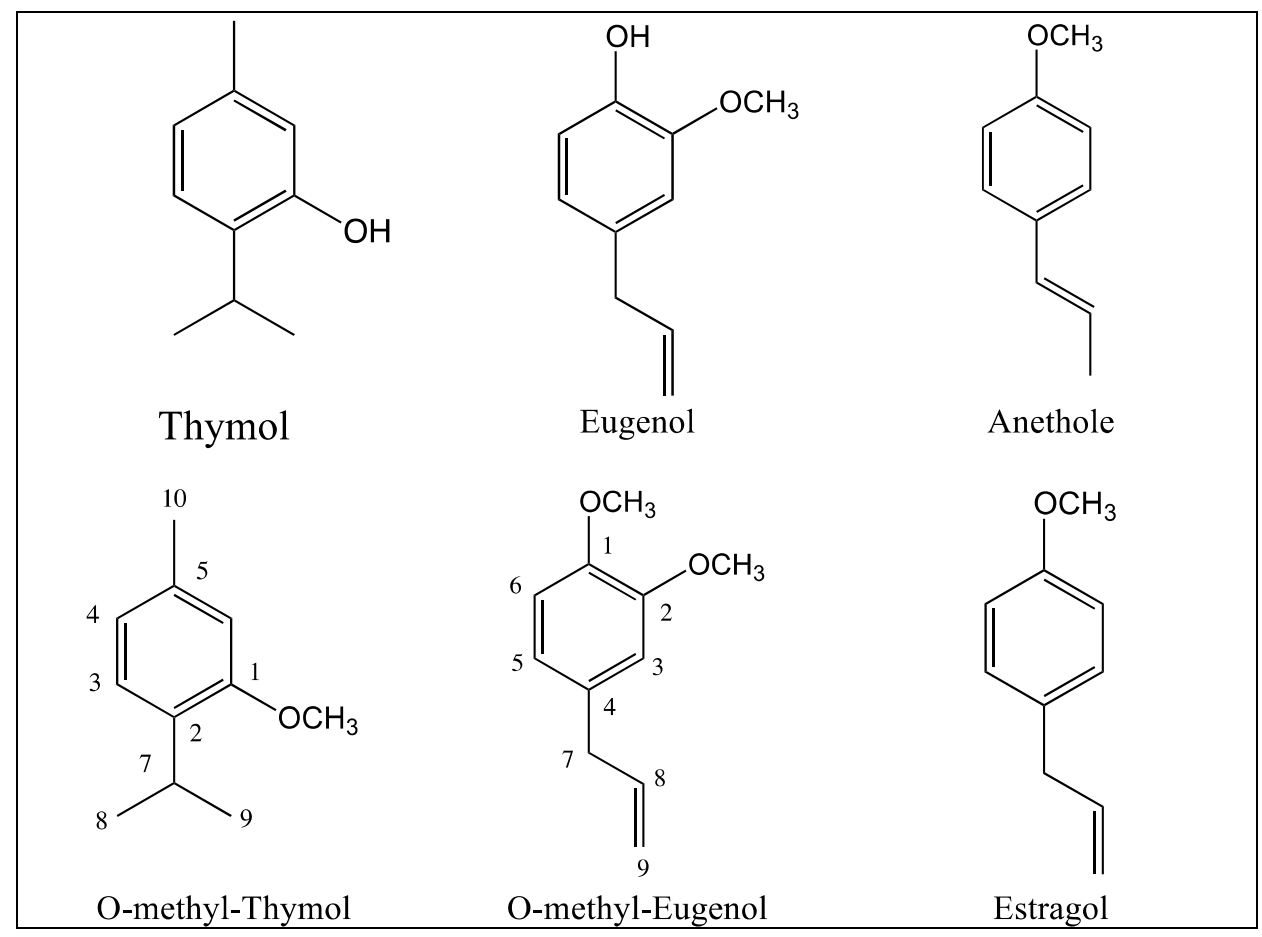

\section{Results and Discussion}

The screening results for the antifungal activity of the alkylphenols (thymol, eugenol, estragole and anethole) and thymol/eugenol methyl-derivatives against $M$. canis and Candida spp. are shown in Table 1, while Table 2 shows the MICs and MFCs of thymol, methylthymol, eugenol, methyleugenol, anethol and estragole against M. canis. A statistically significant difference was observed when comparing MICs $(p=0.0256)$ and MFCs $(p=0.0256)$ for thymol to MICs $(p=0.0231)$ and MFCs $(\mathrm{p}=0.0231)$ for eugenol against $M$. canis strains.

Table 2 also shows the MICs and MFCs of thymol, methylthymol, eugenol, methyleugenol, anethole and estragole against Candida spp. There was statistical significance for the MIC ( $p=0.0196)$ and MFC $(p=0.0196)$ of thymol in relation to the other alkylphenols.

Many essential oils exhibit antioxidant and antimicrobial activities. Phenols, such as thymol, carvacrol, and eugenol, are among the most active natural antioxidants and antimicrobials found in essential oils. However, due to their poor water solubility and the requirement for high concentrations to reach a therapeutic effect, the efficiency of these compounds in treatment is limited [14]. 
Table 1. Screening of antifungal activity of alkylphenols against M. canis and Candida spp. by the agar-well diffusion method.

\begin{tabular}{|c|c|c|c|c|c|c|c|c|}
\hline \multirow[b]{3}{*}{ Strains } & \multicolumn{8}{|c|}{ Growth Inhibition Zones (mm) } \\
\hline & \multicolumn{6}{|c|}{ Alkylphenols $(10,000 \mu \mathrm{g} / \mathrm{mL})$} & \multicolumn{2}{|c|}{ Controls } \\
\hline & thymol & $\begin{array}{l}\text { methyl- } \\
\text { thymol }\end{array}$ & eugenol & $\begin{array}{l}\text { methyl } \\
\text { eugeno }\end{array}$ & anethole & estragole & $\begin{array}{c}\text { griseofulvin } \\
(1000 \mu \mathrm{g} / \mathrm{mL})\end{array}$ & $\begin{array}{c}\text { amphotericin B } \\
(5 \mu \mathrm{g} / \mathrm{mL})\end{array}$ \\
\hline \multicolumn{9}{|l|}{ M. canis } \\
\hline CEMM 01-3-188 & 35 & 22 & 26 & 20 & 16 & 23 & 55 & - \\
\hline CEMM 01-5-190 & 40 & 20 & 30 & 20 & 20 & 20 & 47 & - \\
\hline \multicolumn{9}{|l|}{ C. albicans } \\
\hline CEMM 01-3-075 & 18 & 18 & 12 & 10 & 11 & 11 & - & 14 \\
\hline CEMM 01-3-069 & 17 & 13 & 8 & 7 & 9 & 8 & - & 10 \\
\hline
\end{tabular}

Essential oils rich in alkylphenols frequently present antimicrobial activity [2]. This has been corroborated by several other studies on the effect of essential oils of Croton species and Lippia sidoides, which are rich in thymol, methyl-eugenol, estragole and anethole, and were shown to have antifungal properties against Candida spp. and $M$. canis $[8,10]$. In addition, the antimicrobial activity of thymol was demonstrated against oral pathogens [9]; the inhibitory effects of anethole and eugenol were evaluated based on the growth and toxin production of Aspergillus parasiticus [14].

Eugenol was shown to be effective against fungi isolated from onychomycosis [15]; a fungistatic dodecanol combined with a sublethal amount of anethole showed fungicidal activity against $S$. cerevisiae [16] and the anti-Candida effects of estragole in combination with ketoconazole or amphotericin B was demonstrated [17].

This work demonstrates the great potential of alkylphenols as antifungal agents against Candida spp. and Microsporum canis, as observed by the relevant MIC and MFC levels of thymol, anethole, estragole and methyl-derivatives (methylthymol and methyleugenol). Although all the tested compounds showed MIC and MFC values, which support their antimicrobial activity against fungi of medical interest, thymol stood out for its potent effect in vitro on both the dermatophyte $M$. canis and the Candida spp.

Corroborating these results, Botelho et al. [9] demonstrated that thymol has potent antimicrobial activity against Candida albicans, with minimum inhibitory concentrations ranging from 625 to $10,000 \mu \mathrm{g} / \mathrm{mL}$. More recently, Guo et al. [18] showed the antifungal activity of thymol against clinical isolates of fluconazole-sensitive and -resistant Candida albicans strains. In addition, Gayoso et al. [15] showed that eugenol is a strong antifungal agent against yeast (C. albicans, C. tropicalis, C. krusei) and dermathophytes (T. rubrum and T. mentagrophytes), suggesting this alkylphenol is a promising compound for the development of antifungal drugs. It was also reported that anethole shows synergistic effects on the antifungal activities of phytochemicals against Saccharomyces cerevisiae and C. albicans [16]. 
Table 2. Minimum inhibitory and fungicidal concentrations of alkylphenols against M. Canis and Candida spp. evaluated by the broth microdilution method.

\begin{tabular}{|c|c|c|c|c|c|c|c|c|c|c|c|c|c|c|}
\hline \multirow{3}{*}{ Strains } & \multicolumn{12}{|c|}{ Alkylphenols $(\mu \mathrm{g} / \mathrm{mL})$} & \multicolumn{2}{|c|}{ Controls $(\mu \mathrm{g} / \mathrm{mL})$} \\
\hline & \multicolumn{2}{|c|}{ thymol } & \multicolumn{2}{|c|}{ methyl-thymol } & \multicolumn{2}{|c|}{ eugenol } & \multicolumn{2}{|c|}{ methyl-eugenol } & \multicolumn{2}{|c|}{ anethole } & \multicolumn{2}{|c|}{ estragole } & \multirow{2}{*}{$\frac{\text { amphotericin B }}{\text { MIC }}$} & \multirow{2}{*}{$\frac{\text { griseofulvin }}{\mathrm{MIC}}$} \\
\hline & MIC & MFC & MIC & MFC & MIC & MFC & MIC & MFC & MIC & MFC & MIC & MFC & & \\
\hline \multirow[t]{2}{*}{ C. albicans $(\mathrm{n}=4)$} & $39(4) \mathrm{a}$ & $78(4)$ & $1250(4)$ & $2500(4)$ & $620(3)$ & $1250(3)$ & $620(3)$ & $1250(3)$ & $620(4)$ & $1250(4)$ & $1250(3)$ & $2500(3)$ & $0.5(2)$ & - \\
\hline & & & & & $150(1)$ & $310(1)$ & $310(1)$ & $620(1)$ & & & $620(1)$ & $1250(1)$ & $0.25(2)$ & \\
\hline \multirow[t]{2}{*}{ C. tropicalis $(\mathrm{n}=2)$} & $39(2)$ & $78(2)$ & $1250(1)$ & $2500(1)$ & $310(2)$ & $620(2)$ & $310(2)$ & $620(2)$ & $620(2)$ & $1250(2)$ & $620(2)$ & $1250(2)$ & $1.0(1)$ & - \\
\hline & & & $620(1)$ & $1250(1)$ & & & & & & & & & $0.5(1)$ & \\
\hline C. $k r u s e i(\mathrm{n}=1)$ & 150 & 310 & 1250 & 2500 & 620 & 1250 & 620 & 1250 & 620 & 1250 & 620 & 1250 & 0.5 & - \\
\hline \multicolumn{15}{|l|}{ ATCC 22019} \\
\hline \multicolumn{14}{|l|}{$(\mathrm{n}=1)$} & - \\
\hline \multicolumn{15}{|l|}{ ATCC 6528} \\
\hline \multirow[t]{3}{*}{ M. canis $(\mathrm{n}=6)$} & $9.7(3)$ & $19(3)$ & $150(4)$ & $310(4)$ & $39(6)$ & $78(6)$ & $150(2)$ & $310(2)$ & $150(3)$ & $310(3)$ & $39(4)$ & $78(4)$ & - & $0.25(2)$ \\
\hline & $4.8(3)$ & $9.7(3)$ & $78(2)$ & $150(2)$ & & & $78(4)$ & $150(4)$ & $78(3)$ & $150(3)$ & $19(2)$ & $39(2)$ & & $0.125(3)$ \\
\hline & & & & & & & & & & & & & & $0.006(1)$ \\
\hline
\end{tabular}

${ }^{a}$ Represents the number of strains of a species for the MIC and MFC indicated. 


\section{Experimental}

\subsection{General}

Estragole, anethole and eugenol were purchased from Sigma Chemical Co. (St. Louis, MO, USA) and thymol was supplied by Vetec (Duque de Caxias, RJ, Brazil). The methyl-derivatives were synthesized as previously described by Furniss et al. [13]. Briefly, eugenol or thymol (0.05 mol) was suspended in a cold solution of $\mathrm{NaOH}(13.3 \mathrm{~g}, 0.33 \mathrm{~mol})$ in water $(81.25 \mathrm{~mL})$ with vigorous stirring. Dimethyl sulfate $(14.4 \mathrm{~g}, 0.12 \mathrm{~mol})$ was added in one portion, and the mixture was shaken vigorously for 20 minutes, while the temperature was maintained below $35^{\circ} \mathrm{C}$ by external cooling. A second portion of dimethyl sulfate $(14.4 \mathrm{~g}, 0.12 \mathrm{~mol})$ was added and the temperature was allowed to rise to $40-45{ }^{\circ} \mathrm{C}$. At the end of the reaction, the reaction mixture was transferred to a separatory funnel. The organic layer, containing the methyl-derivatives, was washed with distilled water and dried with anhydrous sodium sulfate. The solvent was then evaporated to furnish the corresponding methyl derivatives. The chloroform was eliminated in a rotary evaporator to obtain pure methyl derivatives, which were analyzed by ${ }^{1} \mathrm{H}-,{ }^{13} \mathrm{C}-\mathrm{NMR}$ and mass spectroscopy [19]. The presence of the absorption band in $55.2 \delta$ of the $\mathrm{OCH}_{3}$ group in the ${ }^{13} \mathrm{C}$-NMR and the corresponding peak at $3.87 \delta$ in the ${ }^{1} \mathrm{H}-\mathrm{NMR}$ spectrum of $O$-methylthymol confirmed the methylation of thymol. In the spectra of $O$-methyl-eugenol, the mass spectra confirmed the molecular mass at $\mathrm{m} / \mathrm{z} 178$, in the ${ }^{1} \mathrm{H}-\mathrm{NMR}$ spectrum two peaks at $3.88 \delta$ and $3.90 \delta$ appeared, while in the ${ }^{13} \mathrm{C}$-NMR there were also two peaks for the methoxyl groups at $55.7 \delta$ and $55.9 \delta$. The spectral data of the methyl derivatives of thymol and eugenol are listed below.

O-Methylthymol. ${ }^{13} \mathrm{C}-\mathrm{NMR}\left(\delta, \mathrm{CDCl}_{3}\right): 155.6(\mathrm{C} 1), 136.3(\mathrm{C} 2), 126.8(\mathrm{C} 3), 121.1(\mathrm{C} 4), 134(\mathrm{C} 5)$, 111.4 (C6), $25.4(\mathrm{C} 7), 22.8(\mathrm{C} 8), 22.8(\mathrm{C} 9), 21.3(\mathrm{C} 10), 55.2\left(\mathrm{OCH}_{3}\right) .{ }^{1} \mathrm{H}-\mathrm{NMR}\left(\delta, \mathrm{CDCl}_{3}\right): 1.26(\mathrm{~d}$, 6.4, $\left.\mathrm{CH}_{3} 8 / \mathrm{CH}_{3} 9\right), 2.39$ (s, $\left.\mathrm{CH}_{3} 7\right), 3.34$ (h, 6.4, H7), 3.87 (s, $\left.\mathrm{OCH}_{3}\right), 6.73(\mathrm{~s}, \mathrm{H} 6), 6.81$ (d, 5.6, H3), $7.17(\mathrm{~d}, 5.6, \mathrm{H} 4)$.

O-Methyleugenol. MS-EI m/z (Int. \%): 178 (100), 163 (45), 151 (15), 147 (50), 131 (14), 115 (26), 103 (78), 91 (84), 77 (39), 65 (38), 51 (22). ${ }^{13} \mathrm{C}-\mathrm{NMR}\left(\delta, \mathrm{CDCl}_{3}\right): 147.3(\mathrm{C} 1), 148.8(\mathrm{C} 2), 111.2(\mathrm{C} 3)$, 132.6 (C4), 120.4 (C5), 111.8 (C6), 39.7 (C7), 137.8 (C8), 115.6 (C9), 95.9 (C10), 95.7 (C11). ${ }^{1} \mathrm{H}-\mathrm{NMR}\left(\delta, \mathrm{CDCl}_{3}\right): 3.36(\mathrm{~d}, 2.5, \mathrm{H} 7), 3.88\left(\mathrm{OCH}_{3}\right), 3.90\left(\mathrm{OCH}_{3}\right), 5.09(\mathrm{dd}, 9.3 ; 2.9, \mathrm{H} 9), 5.98$ (m, H8), 6.76 (d, 4.7, H-5), 6.83 (m, H3, H6).

\subsection{Fungal strains}

The strains were obtained from the fungus collection of the Specialized Medical Mycology Center-CEMM (Federal University of Ceará, Brazil), where they were maintained in saline $(0.9 \%$ $\mathrm{NaCl}$ ), at $28^{\circ} \mathrm{C}$. At the time of the analysis, an aliquot of each suspension was taken and inoculated on potato dextrose agar (DIFCO, Detroit, MI, USA), and then incubated at $28{ }^{\circ} \mathrm{C}$ for $2-10$ days. A total of six strains of $M$. canis and six Candida spp. (four C. albicans and two C. tropicalis) were included in this study. Both M. canis and Candida spp. strains were isolated from dogs. In addition, C. parapsilosis (ATCC 22 019) and C. krusei (ATCC 6528) strains were used as a quality controls. 


\subsection{Agar-well diffusion method}

The inocula preparation for the agar-well diffusion method was carried out as previously described $[8,10,20]$. The screening of the antifungal activity of the alkylphenols and methyl derivatives of thymol and eugenol was performed against Candida spp and M. canis strains by the agar-well diffusion method, as previous reported $[8,10,20]$. In brief, Petri dishes $(15 \mathrm{~cm}$ in diameter) were prepared with potato dextrose agar (DIFCO) and then wells (6 $\mathrm{mm}$ in diameter) were cut from the agar. Each fungal suspension was inoculated on the surface of the agar and $0.100 \mathrm{~mL}$ of each suspension was placed into the wells. After incubation at $28{ }^{\circ} \mathrm{C}$, for $3-5$ days for Candida spp. and 5-8 days for M. canis, all the dishes were examined for growth-inhibition zones and the diameters of these zones were measured in millimeters. Each experiment was repeated at least twice. The alkylphenols and methyl-derivatives were dissolved in DMSO to obtain a test concentration of $10,000 \mu \mathrm{g} / \mathrm{mL}$. griseofulvin $(1000 \mu \mathrm{g} / \mathrm{mL}$; Sigma Chemical Co.) and amphotericin B (5 $\mu \mathrm{g} / \mathrm{mL}$; Sigma Chemical Co.) were prepared in distilled water and tested as positive controls for $M$. canis and Candida spp., respectively.

\subsection{Broth microdilution method}

For the broth microdilution method, the inocula preparation was carried out as previously described [6-8,10]. The minimum inhibitory concentration (MIC) for Candida spp. was determined by the broth microdilution method, in accordance with the Clinical and Laboratory Standards Institute-CLSI (formerly NCCLS; M27-A2) [21]. The broth microdilution assay for M. canis was performed as described by Jessup et al. [22], Fernandez-Torres et al. [23], and Brilhante et al. [24], based on the M38-A document [25]. The minimum fungicidal concentrations (MFC) for both Candida spp. and M. canis were found according Fontenelle et al. [8].

The microdilution assay was performed in 96-well microdilution plates and the alkylphenols were tested in concentrations ranging from 4 to $5,000 \mu \mathrm{g} / \mathrm{mL}$. Growth and sterile control wells were included in each experiment. The microplates were incubated at $37{ }^{\circ} \mathrm{C}$ and read visually after two days for Candida spp. and five days for $M$. canis, as previously reported [6,7,10,20,23,25]. All isolates were run in duplicate. The MIC was defined as the lowest alkylphenol concentration that caused $100 \%$ inhibition of visible fungal growth. The results were read visually as recommended by CLSI. The MFC was determined by subculturing $100 \mu \mathrm{L}$ of solution from subsequent MIC well on potato dextrose agar at $28{ }^{\circ} \mathrm{C}$. The MFCs were determined as the lowest concentration resulting in no growth on the subculture after two days for Candida spp. and five days for M. canis $[6-8,10]$.

\subsection{Statistical analysis}

The MICs and MFCs of the aromatic compounds and methyl derivatives were analyzed by the Wilcoxon and Friedman tests. The result was considered significant at $p<0.05$. The followings comparisons were carried out: thymol $v s$. methyl-thymol; eugenol $v s$. methyl-eugenol; and differences among the isolated alkylphenols. 


\section{Conclusions}

Our results demonstrate that alkylphenols showed in vitro antifungal activity against Candida spp. and M. canis. Since thymol and eugenol are skin irritants, further studies should be carried out to establish whether or not methyl derivatives of thymol and eugenol possess better pharmacokinetics and safety characteristics than their parent compounds for in vivo usefulness.

\section{Acknowledgements}

We acknowledge the financial support of FUNCAP (Ceará State Research Foundation) and CNPq (National Counsel for Technological and Scientific Development; Brazil, Proc. CNPq: 307402/2010-0; Proc. CNPq: 562296/2010-7).

\section{References}

1. Chermette, R.; Ferreiro, L.; Guillot, J. Dermatophytoses in animals. Mycopathologia 2008, 166, 385-405.

2. Harris, R. Progress with superficial mycoses using essential oils. Int. J. Aromather. 2002, 12, 83-91.

3. Gupta, A.K.; Cooper, E.A. Update in antifungal therapy of dermatophytosis. Mycopathologia 2008, 166, 353-367.

4. Martinez-Rossi, N.M.; Peres, N.T.; Rossi, A. Antifungal resistance mechanisms in dermatophytes. Mycopathologia 2008, 166, 369-383.

5. Lewis, R.E. Overview of the changing epidemiology of candidemia. Curr. Med. Res. Opin. 2009, $25,1732-1740$.

6. Brito, E.H.S.; Fontenelle, R.O.S.; Brilhante, R.S.N.; Cordeiro, R.A.; Soares Junior, F.A.; Sidrim, J.J.C.; Rocha, M.F.G. Phenotypic characterization and in vitro antifungal sensitivity of Candida spp. and M. pachydermatis strains from dogs. Vet. J. 2007, 174, 147-153.

7. Brito, E.H.S.; Brilhante, R.S.N.; Cordeiro, R.A.; Sidrim, J.J.C.; Fontenelle, R.O.S.; Melo, L.M.; Albuquerque, E.S.; Rocha, M.F.G. The anatomical distribution and antimicrobial susceptibility of yeast species isolated from healthy dogs. Vet. J. 2009, 182, 320-326.

8. Fontenelle, R.O.S.; Morais, S.M.; Brito, E.H.S.; Kerntopf, M.R.; Brilhante, R.S.N.; Cordeiro, R.A.; Tomé, A.R.; Queiroz, M.G.R.; Nascimento, N.R.F.; Sidrim, J.J.C.; et al. Chemical composition, toxicological aspects and antifungal activity of essential oil from Lippia sidoides Cham. J. Antimicrob. Chem. 2007, 59, 934-940.

9. Botelho, M.A.; Nogueira, N.A.P.; Bastos, G.M.; Fonseca, S.G.C.; Lemos, T.L.G.; Matos, F.J.A.; Montenegro, D.; Heukelbach, J.; Rao, V.S.; Brito, G.A.C. Antimicrobial activity of the essential oil from Lippia sidoides, carvacrol and thymol against oral pathogens. Braz. J. Med. Biol. Res. 2007, 40, 349-356.

10. Fontenelle, R.O.S.; Morais, S.M.; Brito, E.H.S.; Brilhante, R.S.N.; Cordeiro, R.A.; Nascimento, N.R.F.; Kerntopf, M.R.; Sidrim, J.J.C.; Rocha, M.F.G. Antifungal activity of 
essential oils of Croton species from the Brazilian Caatinga biome. J. Appl. Microbiol. 2008, 104, 1383-1390.

11. Soković, M.D.; Vukojević, J.; Marin, P.D.; Brkić, D.D.; Vajs, V.; Van Griensven, L.J. Chemical composition of essential oils of Thymus and Mentha species and their antifungal activities. Molecules 2009, 14, 238-249.

12. Pinto, E.; Vale-Silva, L.; Cavaleiro, C.; Salgueiro, L. Antifungal activity of the clove essential oil from Syzygium aromaticum on Candida, Aspergillus and dermatophyte species. J. Med. Microbiol. 2009, 58, 1454-1462.

13. Furniss, B.S.; Hannaford, A.J.; Smith, P.W.G.; Tatchell, A.R. Vogel's Textbook of Pratical Organic Chemistry; Longman Scientific \& Technical: London, UK, 1989.

14. Karapinar, M. Inhibitory effects of anethole and eugenol on the growth and toxin production of Aspergillus parasiticus. Food Microbiol. 1990, 10, 193-199.

15. Gayoso, C.W.; Lima, E.O.; Oliveira, V.T.; Pereira, F.O.; Souza, E.L.; Lima, I.O.; Navarro, D.F. Sensitivity of fungi isolated from onychomycosis to Eugenia cariophyllata essential oil and eugenol. Fitoterapia 2005, 76, 247-249.

16. Fujita, K.; Fujita, T.; Kubo, I. Anethole, a potential antimicrobial synergist, converts a fungistatic dodecanol to a fungicidal agent. Phytother. Res. 2007, 21, 47-51.

17. Shin, S.; Pyun, M.S. Anti-Candida effects of estragole in combination with ketoconazole or amphotericin B. Phytother. Res. 2002, 18, 827-830.

18. Guo, N.; Liu, J.; Wu, X.; Meng, R.; Wang, X.; Xiang, H.; Deng, X.; Yu, L. Antifungal activity of thymol against clinical isolates of fluconazole-sensitive and -resistant Candida albicans. J. Med. Microbiol. 2009, 58, 1074-1079.

19. Adams, R.P. Identification of Essential Oil Components by Gas Chromatography/Quadrupole Mass Spectroscopy; Allured Publishing Corporation: Carol Stream, IL, USA, 2005.

20. Gurgel, L.A.; Sidrim, J.J.C.; Martins, D.T.; Cechinel-Filho, V.; Rao, V.S. In vitro antifungal activity of dragon's blood from Croton urucurana against dermatophytes. J. Ethnopharmacol. 2005, 97, 409-412.

21. National Committee for Clinical Laboratory Standards. Reference Method for Broth Dilution Antifungal Susceptibility Testing of Yeasts-Second Edition: Approved Standard M27-A2; Clinical and Laboratory Standards Institute, NCCLS: Villanova, PA, USA, 2002.

22. Jessup, C.J.; Warner, J.; Isham, I.; Hasan, I.; Ghannoum, M.A. Antifungal susceptibility testing of dermatophytes: establishing a medium for inducing conidial growth and evaluation of susceptibility of clinical solates. J. Clin. Microbiol. 2000, 38, 341-344.

23. Fernandez-Torres, B.; Cabanes, F.J.; Carrillo-Munoz, A.J.; Esteban, A.; Inza, I.; Abarca, L.; Guarro, J. Collaborative evaluation of optimal antifungal susceptibility testing conditions for dermatophytes. J. Clin. Microbiol. 2002, 40, 3999-4003.

24. Brilhante, R.S.N.; Cordeiro, R.A.; Medrano, D.J.; Monteiro, A.J.; Sidrim, J.J.C.; Rocha, M.F.G. Antifungal susceptibility and genotypical pattern of Microsporum canis strains. Can. J. Microbiol. 2005, 51, 507-510. 
25. National Committee for Clinical Laboratory Standards. Reference Method For Broth Dilution Antifungal Susceptibility Testing of Filamentous Fungi: Approved Standard, M38-A; Clinical and Laboratory Standards Institute, NCCLS: Villanova, PA, USA, 2002.

Sample Availability: Not available

(C) 2011 by the authors; licensee MDPI, Basel, Switzerland. This article is an open access article distributed under the terms and conditions of the Creative Commons Attribution license (http://creativecommons.org/licenses/by/3.0/). 